\title{
Language Raising, Empowerment and Development: The Case of Shona Language at Great Zimbabwe University
}

\author{
Mickson Mazuruse \\ Department of Curriculum Studies, Great Zimbabwe University, Masvingo, Zimbabwe \\ Email: mickson_mazuruse@yahoo.co.uk \\ Edgar Nhira Mberi \\ Faculty of Arts, University of Zimbabwe, Harare, Zimbabwe \\ Email: mberiuk@yahoo.co.uk
}

\begin{abstract}
Many academic papers have been written by African scholars calling for the greater use of African languages in all facets of communication in Africa. Politicians in many African countries have called for a greater role for African languages in developmental programmes in Africa. This research attempts to move away from the usual moaning that has characterised many conferences on African linguistics where a lot of time is spent on lambasting the lack of political will in implementing language policies that promote African languages. This study argues that the best way to promote indigenous languages is not to spend too much time "talking about promotion of indigenous languages" but to provide tangible products that enable the speakers of these languages to transmit traditional as well as modern knowledge in these languages. Such products include dictionaries, glossaries, electronic corpora and other reference works. This paper looks at one of these developments that have significantly contributed to the promotion and development of indigenous languages in Zimbabwe. It discusses the efforts by one institution that has played a major role in the promotion of indigenous languages in Zimbabwe, that is, the Great Zimbabwe University in Masvingo, Zimbabwe. The main focus is on the challenges faced by this institution and the strategies being employed in the efforts to develop terminologies that equip the indigenous languages with the abstractive powers that are needed for people to be able to teach all Shona courses at tertiary level in the medium of Shona. The article argues that the use of these languages at tertiary level will result in them playing a much bigger role at national level.
\end{abstract}

Index Terms - language raising, language empowerment, language development, translation, common underlying hypothesis, code switching and code-mixing

\section{INTRODUCTION}

This article takes a close look at the crucial question of which language(s) to use for teaching and learning at tertiary institutions especially in former colonial countries because it is the key to the access of knowledge. Taking the Great Zimbabwe University (GZU) as a case study, this article highlights some of the problems of language development that linguists face in their bid to empower a language. The article explores some of the strategies the linguists at GZU have adopted in dealing with the critical issue of language prioritization for development within the context of a difficult linguistic background.

What spurred this research is the realization that, "universities in Zimbabwe have not yet reached a consensus as to which medium to use when teaching African languages..." (Chapanga and Makamani, 2006, p.386). It is intriguing that the situation obtaining at the University of Zimbabwe (UZ) and Midlands State University (MSU) where lectures continue the use of English as medium of instruction in teaching indigenous languages, while at Great Zimbabwe University (GZU) the medium of instruction for similar courses is Shona (Chapanga and Makamani, 2006). The GZU approach, which is now widely known as the Great Zimbabwe University model, is already teaching indigenous languages using the mother tongue as medium of instruction. The present efforts at Great Zimbabwe University to use Shona language as a medium of instruction in all Shona courses is an act of language raising in the way they give the language abstractive powers that it needs to describe itself. This is a way of empowering indigenous languages like Shona which have been downgraded to the informal and unofficial domains in the colonial and post-colonial dispensations.

Language raising refers to the elevation or upgrading of a particular language so that the language can assume several functions previously not assigned to it, for example, that of educational instruction and general government administration. Language raising in this paper is taken to mean, "the upliftment of the status of a 'low variety' language by diversifying its functions to cope with development and modernization to the level where it can be used in sectors which were previously the preserve of a 'higher variety' language like English, in the case of Zimbabwe..." 
(Chimhundu: 2005a, p.1). Anyidoho (1992), Ngugi (1987) and Uju (2008) present similar opinions on language as a liberating force to reckon with in terms of empowering its speakers if it is empowered.

The general understanding that goes with the use of the term, language development, is that, "the communicative function of the developed language is enhanced and its status is raised..." (Chabata, 2008, p.16). It can be noted that the use of Shona as a medium of instruction at GZU plays a very significant role in the process of the development of the Shona language. This research argues that, the project of developing and empowering Shona language to a level where it can be used in modern science and technology is a process which needs a long term strategy. The foundation on which the process has to be constructed should be supported by, terminography,translation, development of study materials and the general expansion of lexical to incorporate ideas borrowed from other languages. The conceptualization of the research comes from the realization that knowledge that has been developed in the many different languages today was initially in a language that was later translated to another language.

\section{BACKGROUND}

Great Zimbabwe State University has pioneered the use indigenous languages as media of instruction in indigenous languages courses. The use of indigenous languages as media of instruction is a University policy which is in line with the vision and mission of the university. The vision is to provide a learning environment for the search of new knowledge and experiences through creativity and cultural enrichment as a strategy for solving real life developmental and existential problems. The mission is for the university to be the centre of excellence in creative arts, culture and technology as a basis for reclaiming our heritage and our rightful position in a globalised world (Great Zimbabwe University Information services). The Great Zimbabwe University seeks to play a dominant role, not only in the restoration and preservation of Zimbabwean culture, but also in using culture as a basis upon which to build the future within the context of current global and local imperatives. The university's curriculum reflects those elements that promote our culture, reinforce our dignity and self-confidence and underpin national unity.

Efforts at Great Zimbabwe University to use Shona as a medium of instruction in academic studies are centred on the creation of relevant terminology to use in all the courses on offer in the Shona subject area. Lecturers and students at GZU have to meet the demands of having to read and refer to sources written in English and satisfy the requirements of lecturing, learning, writing assignments and exams in Shona. There is need to strategise to create terms at the moment before a planned process through, borrowing, indigenous systems and linguistic engineering. Although the transition from English to indigenous languages as medium of instruction in education helps to destroy the myth that knowledge of English is necessarily a pre-requisite for transmitting modern knowledge, there are difficulties like the absence of technical terms, textbooks and proficient lecturers.

\section{THEORETICAL FRAMEWORK}

The research is guided by Cummins' Language Transferability theory or Additive Model of Common Underlying Proficiency (CUP) in language learning. According to Cummins (1984), effective learning is facilitated when the student's mother tongue is allowed to further develop whilst using a second language to understand certain aspects. Cummins's model is applicable in bilingual contexts like the one at Great Zimbabwe University, where both Shona and English are instrumental in the transmission of knowledge. The Shona language is the primary medium of instruction and English only comes in for judicious purposes to complement the primary language and at the same time using the second language in ways that meet the students' needs. Several studies have shown that overall academic achievement is higher among bilingual students whose mother tongue is more positively incorporated into the educational system (Hamers and Blanc, 1989). As Cummins (2000) states, "conceptual knowledge developed in one language helps to make input in the other language comprehensible..." (p.38). Kroll (1990) quotes Cummins claiming that, "there is an "underlying cognitive/academic proficiency" common to languages and this enables transfer of literacy related skills across languages..." (p.95). In this regard, students are not expected to give up their language and identity and replace them with new ones, but they are expected to add a second language to their repertoire which shows the additive nature of this principle. Cummins argues that when concepts are learned in one language, they can later be expressed in another language without having to be relearned.This means if a student understands the concept of 'Afrocentricity' in one language, all the student has to do is acquire labels of these terms in another language. A child who has learned the concept of 'Afrocentricity' in one language would not need to be relearning the same concept in another language. As a matter of policy, the Shona language should be the primary medium of instruction. However, English continues to be used alongside Shona until such a time when Shona is ready to have independent existence. A more progressive way of looking at the situation is whereby systems should allow and encourage more interdependence between English and Shona language the approach embraced by the Common Underlying Proficiency hypothesis.

\section{Methodology}

In order to carry out this research, written sources, questionnaires, interviews and observations were used. This method of collecting data in many different ways was chosen because the use of varied instruments enabled the researcher to gather useful information from respondents to validate the findings of the study. The design borrows from 
both the scientific and interpretive paradigms and the results are triangulated for validation of results. This is a desirable measure "to cross-check the validity of data and the derived conclusions" (UNESCO, 1999, p.11). It is hoped that this provides a clearer picture of the challenges of the use of Shona as a medium of instruction at university level. The representative data collected through questionnaires, interviews, written sources and observations was helpful in as far as it provided recurrent patterns for conclusions to be drawn and theories or generalizations to be made. The overall aim in using the research methods outlined above is to help substantiate and also analyze the observations that were made during the course of this study.

\section{Challenges}

\section{A. Problem of Failing to Use Shona Exclusively in the Deliverance of Lectures and Strategies Being Taken}

Although the elaboration and modernization of African languages would enable them to be used as languages media for the teaching of African languages in their own medium, the necessary terminology to ensure efficiency in this process is lacking. English terms and foreign terms continue to be adapted and adopted where indigenous terms do not exist. This has been highlighted by Ngugi (1994) when he said that, "the language of the African child's formal education is foreign, the language of the books he reads is foreign and this has left the children without a language in the classroom..." (p.15). Code switching is one of the strategies being adopted at Great Zimbabwe University to rectify this problem. Studies of code switching in Kenya (Ogutu, 2006) have shown that learners and instructors may switch to another language during learning when they want to do the following:

(a) Facilitate student comprehension

(b) Enhance student interest, response and participation

(c) Break classroom tension

(d) Prevent boredom and fearfulness

(e) Facilitate self expression and communication

(f) Reprimand or correct faults. (p. 43).

There are situations whereby the concepts being learnt are first introduced to the lecturers and students in English, these concepts are more easily accessible in English than in Shona. All the lecturers in the ChiShona subject area learnt all the concepts they teach in English, and they experience difficulties in articulating them using Shona only. These concepts are new to lecturers and students and do not have translations for them in the indigenous language because the technical vocabulary includes words that are specific to particular disciplines like phonetics, phonology, dialects, lexicography or translation. The lecturers and students have a double task of concept learning and meaning making. This problem is worsened by the fact that, there are no textbooks yet in Shona language for university learning, so lecturers and students research in English texts, but use Shona in lectures. Lecturers and students then resort to codeswitching and code-mixing because of lack of ability in using Shona alone.

The majority of interviewees admitted that, although the university policy categorically states the need for the exclusive use of indigenous languages in learning, African languages at Great Zimbabwe University, there is a general tendency to use Shona and English in learning Shona. It is difficult to quantify the extent of lecturer's switch to English language during their lectures, because the amount of English used tends to vary with the type of course content being taught. To show this variation, the study presents two tables from two different lecture observations. A tape recorder was used to capture the data below during lecture observations;

TABLE 1

THE EXTENT OF THE USE OF ENGLISH AND SHONA IN A PHONETICS AND PHONOLOGY SHONA LECTURE

\begin{tabular}{|l|l|l|l|}
\hline Number & Type of sentences & Frequency & Percentage \\
\hline 1 & All Shona & 252 & 64.95 \\
\hline 2 & All English & 10 & 2.58 \\
\hline 3 & Shona mixed with English & 126 & 32.47 \\
\hline 4 & Total number of sentences & 388 & 100 \\
\hline
\end{tabular}

Table 1 show that the Phonetics and Phonology Shona lecture contains $64.95 \%$ of all Shona sentences and about $2.58 \%$ of all English sentences and about $32.47 \%$ of Shona mixed with English sentences. Four out of six interviewed lecturers and forty out of fifty students who responded to questionnaires see nothing wrong in using English to explain technical terminology but, a few others informed by a 'purist' view, are against the mixture of languages in university learning. In all of the lectures on Phonology and Phonetics observed by this researcher, the lecturers alternated Shona and English within the same lectures so often. Following is Table 2 which presents results for the observation for a lecture on literature, 'uvaranomwe': 
TABLE 2

THE EXTENT OF THE USE OF ENGLISH AND SHONA IN A LITERATURE SHONA LECTURE

\begin{tabular}{|l|l|l|l|}
\hline Number & Type of sentence & Frequency & Percentage \\
\hline 1 & All Shona & 252 & 86.2 \\
\hline 2 & All English & 18 & 6.2 \\
\hline 3 & Shona mixed with English & 22 & 7.6 \\
\hline 4 & Total number of sentences & 292 & 100 \\
\hline
\end{tabular}

Table 2 above shows that, the literature lecture contains $86.2 \%$ all Shona sentences, $6.2 \%$ all English sentences and $7.6 \%$ of Shona mixed with English sentences. It can be noted from the two tables that, the extent of the use of English language in Shona lectures vary depending on the nature of the lecture being conducted. A general observation is that, lectures of courses with more technical terms like phonology, phonetics and translation tend to have more frequency of code switching and code-mixing than lectures with fewer technical terms like the literature lectures. The questionnaire results in the table below show how course content determines language of instruction preferences:

Question: Which language should be used to teach you the following course content in your university studies?

TABLE 3.

RESPONSES TO STUDENTS' CHOICE OF LANGUAGE TO BE USED IN TEACHING DIFFERENT COURSES AT GREAT ZIMBABWE UNIVERSITY

\begin{tabular}{|l|l|l|l|l|}
\hline Course content & English & Shona & Both & 100 \\
\hline $\begin{array}{l}\text { Uvaranomwe } \\
\text { (Literature) }\end{array}$ & $0(0 \%)$ & $90(90 \%)$ & $10(10 \%)$ & 100 \\
\hline $\begin{array}{l}\text { Zvidzidzo zvekuturikira } \\
\text { Translation) }\end{array}$ & $20(20 \%)$ & $30(30 \%)$ & $50(50 \%)$ & 100 \\
\hline $\begin{array}{l}\text { Kuumbwa kwemutauro } \\
\text { (Grammar) }\end{array}$ & $25(25 \%)$ & $40(40 \%)$ & $35(35 \%)$ & 100 \\
\hline $\begin{array}{l}\text { Fonoroji nefonetikisi } \\
\text { (Phonology and phonetics) }\end{array}$ & $50(50 \%)$ & $5(5 \%)$ & $45(45 \%)$ & \\
\hline
\end{tabular}

Some of the reasons of the above-preferred choices of language of instruction to be used in different courses are shown below:

TABLE 4

REASONS FOR PREFERRED CHOICES OF LANGUAGE OF INSTRUCTION

\begin{tabular}{|l|l|}
\hline Language Preferred & Reasons for the choice \\
\hline Shona & Shona terminology in literature and grammar is now available. \\
\hline English & English have terminology in translation, phonology and phonetics, which Shona does not have. \\
\hline Both & English complements Shona on literary terms which Shona does not have. \\
\hline
\end{tabular}

The above table shows that the major reason for switching to English language during Shona lectures is primarily because of lack of relevant terminology in Shona on technical terms. English language represents the dominantly used language in academic disciplines explaining the reason why technical terms exist only in $(\mathrm{H})$ form. Sometimes it happens that, the idea is not easily expressible in Shona as it is in English. Other instances are on the use of repetition whereby content is repeated by switching to another language with the intention of emphasizing and making an explanatory choice. The lecturers use the indigenous code and then assesses the students' reaction then use the English code and decide which one of the two receives the more favorable response. Generally lecturers choose a language which students comprehend on a particular instance in their learning. The purpose of this is to find out whether the use of both Shona and English in a lecture assists the eradication of alternate conceptions and acquisition of technical knowledge.

Observations made in lecture deliverances illustrate how Shona is interlaced with English. In one of the lectures in translation, the researcher observes instances of code-switching and code-mixing. When the lecturer askes students, 'ndekupi kudyidzana kunofanirwa kuvapo pakati pemutaurobviwa nemutauronangwa?' (What relationship must be there between source language and the target language?) students cannot understand the gist of the question. When the lecturer rephrases it to; 'Ndati, source language netarget language zvinodyidzana sei?' that is when students started giving positive responses. Code switching is taken as an extra resource by lecturers for lexical items that may not be available in the Shona language such as words like aspiration, vocal tract, supraglottal and several others. New concepts originating in English language are usually better understood by bridging the gap between the source language and the target language. In literature lectures instances of code-mixing are equally prevalent. A lecturers was observed saying; " $p$ 'Bitek anoti, the artist is the ruler, kureva kuti munyori anotarisirwa kupa mutongo akamira pachokwadi." (P'Bitek says, the artist is the ruler to mean that the writer is expected to give a judgment based on the truth.) Another lecturer was also observed saying, "Mungoshi ane defeatist attitude nokuti haapi masolutions kumaproblems anobudiswa nevatambi vake." (Mungoshi has a defeatist attitude because he does not give solutions to problems depicted by his characters.) It is clear that; code-switching or code-mixing becomes the lecturers' strategy for coping with content unfamiliar to students. Since students learn better when they understand what the lecturer is saying, codeswitching becomes a useful resource to get the subject matter across. In this context, code-switching seems to be 
motivated by a need to approach learning from the known to the unknown. Observations from these different lectures show that English and Shona are two complementary languages.

There is an advantage in bilingual contexts of offering students a choice. It is consistent with Cummins' Common Underlying Proficiency Model which offers a refreshing sociolinguistic perspective regarding motivation for the choices speakers make in terms of the back and forth movements across languages within bilingual contexts. Cummins' Language Transferability Theory addresses issues related to topic where deficiencies noticeable in a particular language are covered for by the other language thus highlighting the interdependent relationship between languages. Code switching and code mixing mostly occur where the syntaxes of the languages align in a sentence, since even unrelated languages often align syntactically. This confirms Cummins's argument that, there is an "underlying cognitive/academic proficiency" common to languages and this enables transfers of literacy related skills across languages. If native speakers feel a foreign word is an appropriate designation, they may accept it even if they do not know its etymological origins.

\section{B. Challenges in the Creation of Lexicon to Teach Chishona in Shona at University Level and the Strategies Being Taken}

At present, there is no adequate vocabulary in Shona language of concepts being studied at university level. According to Hadebe (2006), "one of the problems that deny indigenous languages their rightful function among its people is the politics of terminology or lack of it which is used as a pretext to keep indigenous languages out of the domain of modern technology confining them to informal roles in society...” (p.225). Term-creation efforts at GZU involve a number of ways of developing terms to be used in Shona lectures. That means creating lexicon to teach Shona in Shona at university level is indeed a necessary prerequisite for the successful use of Shona as media of instruction. Vocabulary acquisition is important in all language teaching and language enhancement activities and even more important in the use of these languages as media of instruction in education.

Once vocabulary growth in the use of Shona has been increased through term-creation, then, the ability of using the language confidently and understanding certain concepts is easy. But, there are certain dangers when terminographers work in isolation or employ new coinages unofficially because it results in lack of uniformity and consistency with regard to the new terms and their application. This causes confusion, so independent and individualistic term creation should be followed by standardization. It is possible that localized term creation efforts may be too artificial and end up imposing new terms on speakers resulting in an exclusive short-lived lexicon which may not be acceptable. The legitimacy of the developed terminology may be questioned since most of the terms are not published, so their use remains confined to the particular institution without any official recognition. This is quite a challenge to lecturers, since term creation is the responsibility of trained terminologists.

Although various ways can be implemented, all should have the ultimate goal of creating terms that are clear, understandable, apt and accepted. Sager (1990) points out that terms which scientific or technical concepts, must fulfill certain conditions or specific international guidelines formulated by ISO (The International Standards Organization). Some of the guidelines are;

- There should be a one- to- one relation between any given term and the concept it represents i.e. any term should ideally refer to one concept and one concept only. This implies that there should be no synonyms and morphological or spelling variants for any specific term.

- A term should conform to the morphology, spelling and pronunciation conventions of the language for which it is intended.

- Without sacrificing precision, terms should be concise and not contain unnecessary information.

- The meaning of the term should be independent of context... (p. 89).

Although Sager (1990) regards the above guidelines as highly idealized and can only be realized in a highly controlled environment, their application to term-creation activities at Great Zimbabwe University helps in assessing the credibility of the efforts from a general perspective. Most term creation strategies at Great Zimbabwe University align towards paraphrasing and borrowing which are 'problematic' ways in as far as the accepted term creation methods are concerned. The Great Zimbabwe University linguists decided to use an additive or incremental approach whereby in the case of limited, terms they borrow or engineer them. It would be more economic, practical and reasonable to build on the resources that already exist. Such an arrangement would broaden and expand the functions of African languages. The efforts by Great Zimbabwe University of language raising face difficulties of lacking standardized terminology which force the lecturers to create their own terminology that is not approved by any central authority. However, it should be noted that, in most cases, if lecturers come across terms that do not have an equivalent in the available dictionary and terminology list they do not have any option but must create new words on the spot.

While the general policy of the ChiShona department is to promote the use of indigenous words over adoptives as much as possible, it's not practical or realistic to prohibit the use of loan words from other languages. Borrowing is one of the methods used at GZU in creating terms to be used in teaching students at university level. Chimhundu (2002) has identified borrowing and compounding as adoption and adaptation. Loan words are accommodated and expressed in the local language structure, in the phonology of the beneficiary. This has to be done in a manner where the created term would relate directly to the concept being referred to and express it clearly. In borrowing both sound and meaning of the adopted English language are accepted although with changes that should follow the Shona orthographic rules so as to 
avoid violating the natural word formation techniques of the Shona linguistic community. Great Zimbabwe University provides a diglossic socio-linguistic situation which may have resulted in borrowing from a language of influence like English. But, observations made show that, the borrowing at Great Zimbabwe University has been necessitated by both the absence of relevant terminology and prestige. Instances of borrowing are resorted to in cases where the linguists come across a concept or object which they have no equivalent word in Shona language. For example, the following words show borrowing:

TABLE 5

BORROWING AS A RESULT OF NEED

\begin{tabular}{|l|l|}
\hline Chishona & English \\
\hline Ogani & Organ \\
\hline Fokasi & Focus \\
\hline Chikoro & School \\
\hline Fonoroji & Phonology \\
\hline Fonetikisi & Phonetics \\
\hline Semandiki firidhi & Semantic field \\
\hline
\end{tabular}

The above table shows that the process of borrowing takes place in bilingual contexts in situations where there is need to convey new concepts introduced through the medium of English. Chimhundu (1983) says, "While Shona is undoubtedly a very rich language in other areas, it has had to borrow a lot on matters that relate to material culture and technology."(p.34). University lecturers at GZU come across several English technical terms they need to convey to their students in their Shona equivalents but they fail to find relevant equivalents so they resort to borrowing. If borrowing involves semantic, morphological and phonological categories, then it is additive rather than subtractive to the learners. In adopting the English terms, Cummins' Transferability Theory of Common Underlying Proficiency between two languages in bilingual contexts can be applied here. Shona and English have different phoneme inventories and syllable structure hence the need to rephonologise English terms to make them fit into the phonological structure of Shona. The words denoted by the English terms are transferred to the Shona forms. English words, which are borrowed, are adapted to the Shona language in a way that makes them appear to be original Shona words. For example, the English word 'school' has been adapted to Shona and is now realized 'chikoro',also 'policeman' has been adapted to Shona and is now realized as 'mupurisa'. It is noticeable that the adopted English words undergo structural changes and now have a Shona CVCV structure. This demonstrates that, "borrowing is not a random or unsystematic linguistic practice, but a systematic process that operates within the rules that govern the Shona language...” (Mheta, 2007, p.142).This also shows that Shona language modernizes most loan words so that morphophonologically they behave like the native Shona language. Prah, (2002) uses King'ei who contends that, "borrowing between languages is a scientific and cultural phenomenon and is therefore not an indication of deficiency in a language at all."(p.115). But, in other cases some English words have not undergone any structural changes on being adopted into Shona. This is direct adoption with slight phonetical changes of foreign loans

Suffice to say that most general languages do borrow, but borrowing becomes a challenge when terms from the source language fail to undergo metamorphosis which makes them distinguishable from it. The resultant words created through borrowing in the target language are nearer, shorter but meaningless. "A mere adoption of the words phonetics and phonology would produce 'fonetikisi' and 'fonoroji' which are pronounceable in ChiShona, concise and precise but they are meaningless...” (Makaudze, 2005, p.6). The 'Shonalised' terms are accepted because they are nearer to English, shorter but meaningless. Borrowing should be done with caution if apt terms have to be created in various areas of the subject. The creation should limit cases of subordination of ChiShona conceptual formulations to those of the language where they come from. According to Makaudze, (2005), "care must be taken to ensure that the practice does not degenerate into 'head-calling', that is, mere creation of terms that are meaningless in ChiShona by merely 'Shonalising' English terms..." (p.6). Every proposed term must be carefully related to the entire matrix or other terms and the Shona people cultural background so that they are intelligible to the speakers of the language. In other words, direct borrowing from European or other languages should be done with caution since such borrowed words do not convey the any meaning initially and such a method produces clumsy sounding words.

Even in cases where ChiShona has its own terms, GZU ChiShona subject area accepts the borrowed counter-parts as in the cases below:

TABLE 6

BORROWING AS A RESULT OF PRESTIGE

\begin{tabular}{|l|l|}
\hline Chishona & English \\
\hline Purofesa/muzvinafundo & Professor \\
\hline Motokari/hambautare & Motor car \\
\hline Chipunu/Chihwepura & Spoon \\
\hline Zvidzidzwa zvekuumbwa kwemaduramazwi/Rekisikirogirafi & Lexicography \\
\hline Kuturikira/Tiranziresheni & Translation \\
\hline Nzvimbotaurwa/Puresi ofu atikuresheni & Place of articulation \\
\hline Mutinhiro wemumhuno/nazari & Nasal \\
\hline
\end{tabular}


The above table shows that, "the co-existence of English language as a prestigious medium of communication with Shona language has had some effects on the borrowing of technical terms..." (Mheta, 2007, p.111). The above cases show borrowing motivated by the diglossic notion of prestigious preference of English than Shona because it has more influence than the indigenous language. Mheta (2007) contends that; "Words are usually borrowed from the prestigious language, not because equivalents do not exist in the borrowing language, but because they are considered to be more prestigious than the existing indigenous words."(p.111). It is also observed that the borrowed terms are more popular than the indigenous coinages because they are more precise and more specific in reference (Mheta, 2007). The English items are consistently rated as less difficult and more familiar than the Shona items because English has been the language frequently used in academic and vocabulary tasks all along than Shona language. Most words would enter Shona language as foreign, but with time they may settle by changing their linguistic characteristics in order to fit into the new linguistic environment. Once words stabilize, they are conventionalized and become part and parcel of the Shona language and might not be perceived as foreign.

In most cases, coining one word to cater for a concept or word from another language fails to capture the whole sense leading to the method of paraphrasing or compounding. Compounding is combining two or more words to form one word which is a compound or a complex nominal construction. Examples of paraphrased and compound words created at GZU are in table 7 below;

TABLE 7

COMPOUND WORDS

\begin{tabular}{|l|l|}
\hline Chishona & English \\
\hline Zvidzidzo zvemabhiitaurwa & Study of speech sounds(Phonetics) \\
\hline Zvidzidzo zveurongwa hwemutinhiro yemabhii & Phonology \\
\hline Mapazi anoumba mitauro & Dialects \\
\hline Nzvimbo inodudzwa bhiitaurwa & Place of articulation \\
\hline Kugadzira maduramazwi & Lexicography \\
\hline Madudzirirwo ebhiitaurwa & Manner of articulation \\
\hline
\end{tabular}

The above combinations show that it is important to create words that are combinations of what is found in the existing vocabulary so as to enhance understanding. The terms above have been created by using words that are already existing in the language as well as a few that have been coined but are apt descriptions of what they convey. For example, the term, bhiitaurwa is a new term coined from the words bhii which literally means sound/letter and taurwa which literally means spoken. If the two are brought together, they produce spoken sound/letter, something close to the phonetic word' speech sound. As can be seen by the above illustrations, compounding is a productive way of creating terms because it effectively conveys the source language concepts.

These terms are too long and clumsy; although the meaning of the original term is not lost. The length of the multilexical items pose a problem when one wants to make constant use of it in writing. Chiwome, (1992) in his discussion on term creation in Shona notes that, "heavy lexical loading, a result of paraphrasing and compounding, leads to undesirably long terms which are user-unfriendly". (p.68). Chimhundu (2002) also notes that, "compounds are arrived at by indirect means hence they are less specific than labels given to new things to the language of the inventors." (p.78). Multi-lexical items are also difficult when it comes to entering in general dictionaries, thereby posing a problem for terminology development. This may explain why Shona speakers prefer borrowed terms, which are equivalent to compounds because they are shorter and easier to use.

Translation has also been a common way of rendering words and concepts in one language into another used at GZU (Makaudze, 2005). Translation is a process of transferring meaning from the source language to the target language by maintaining balance of meaning in the two languages. The common way has been to find word and conceptual equivalents in the target language. The question is whether the technical vocabulary can well be represented in the mother tongue without necessarily compromising the learning of basic concepts and facts. The practical reality in this case study appears to be that, transfer is not occurring easily and readily because of unfamiliar content. It is difficult to have $100 \%$ accuracy in translating an English text to Shona form. Translation equivalence is not wholly achievable owing to the absence of cultural relevance of some Shona and western terms in the Shona terms. Take donzo for instance, it glosses as main aim, but in Shona grammar it is used to denote mood. No stretch of imagination can show compatibility between these two concepts. One needs to know the significance of mood in English first before one could accept donzo as its Shona equivalent. Adopted words could prove to be difficult in the way they lead to ambiguity. The difficulty in achieving translation equivalence in Shona is due to the fact that the translated Shona items are drawn from the unfamiliar content of English items. The Shona word 'gadza' is to make someone sit or put something on fire or put someone in a position of responsibility. It is derived from/-gar- (sit), but it has acquired new meanings which are not easily traceable to 'gara' since besides sitting, the word has acquired more senses that have nothing to do with sitting as it is expressed in 'gara'. This observation is consistent with the idea that, transfer of language skills is facilitated by familiar content.

Since English has been the first language in which most of the ChiShona concepts have been taught, ChiShona can create its own terms by finding out the necessary equivalents in her own language .According to King'ei in Prah (2002), "translation is a very crucial tool for not only enriching the lexicon of the receptor language, but also adding to its body 
of literature, accommodating specialized forms of learning." (p.110). There is linguistic or word for word equivalence sometimes called literal or structural translation. Examples of translation are in table 8 below:

TABLE 8

STRUCTURAL TRANSLATION

\begin{tabular}{|l|l|}
\hline Chishona & English \\
\hline Nzvovera & Vowel \\
\hline Nzvanyira & Consonant \\
\hline Bhasera & By sale \\
\hline
\end{tabular}

The above illustrations entail looking for substitutes in the ChiShona language of terms used when instruction is done in English.The other strategy is textual/syntagmatic equivalence where everything is sacrificed in order to achieve message accuracy. This is illustrated in table 9 below:

TABLE 9

SYNTAGMATIC TRANSLATION

\begin{tabular}{|l|l|}
\hline Chishona & English \\
\hline Rushizhiro & Glottis \\
\hline Nharembozha & Cellphone \\
\hline Chitokoroshi & Memory stick \\
\hline Kunanzva maoko & Asking for a wife \\
\hline
\end{tabular}

The above illustrations show that language can be made simpler and accessible to all learners in their own mother tongue for effective teaching and learning through unpacking technical language and content for pedagogical purposes.

In translation, English technical terms are transferred to the familiar content of Shona traditional culture and settings. The intention is to find out if concepts encountered and learned in English could be used in academic tasks in Shona language. The familiar indigenous knowledge domains given to the Shona terms facilitate the transfer of English concepts. However, it is important to come up with equivalent terms, which do not lose their original English meaning. Translation is consistent with Cummins' Common Underlying Proficiency theory because the process involves the movement of the translator in and out of English and Shona language to find the equivalent terms. This means that, the process of translation requires the understanding of both English and Shona languages and also their cultures. Observations at Great Zimbabwe University ChiShona department show that it can be done as long as the vocabulary is accepted by all and captures the course's essentials.

Despite the above challenges of term creation, GZU ChiShona subject area has been very innovative in expansion of Shona language vocabulary by adding new words to cater for new concepts and new forms of discourse through composition and semantic extension. According to Makaudze, (2005) "composition means the conversion of root morphemes into names of concepts. In this case, known morphemes are converted into significant terms for use."(p.2) The root morphemes that exist in ChiShona include among others, verb roots, where examples are -sek-,-chem-, -taur-, -nong-, etc. A course like Phonetics and Phonology can have terms created using composition. Root morphemes like; zevezer-(whisper). -tamb-, (dance), -sund-(push), -honyer-(murmur/buzz) can be used to create terms for use in phonetics.

TABLE 10

COMPOSITION OF TERMS

\begin{tabular}{|l|l|l|l|}
\hline Root morpheme & Created Term & English Term & Examples \\
\hline -zevezer- & $\begin{array}{l}\text { (nzvanyira) zevezerwa } \\
\text { (whispered consonant) }\end{array}$ & Voiceless consonant & $\begin{array}{l}\mathrm{t}, \text {-tamba } \\
\text { p, -pora }\end{array}$ \\
\hline -tamb- & $\begin{array}{l}\text { (nzvanyira) nhamba } \\
\text { (dancing consonant) }\end{array}$ & Trill & $\begin{array}{l}\text { R ,-ronga } \\
\text {, -rakaraka }\end{array}$ \\
\hline -sund- & $\begin{array}{l}\text { (nzvanyira) sundwa } \\
\text { (pushed consonant) }\end{array}$ & Flap & v, -kovo-o \\
\hline -honyer- & $\begin{array}{l}\text { (nzvanyira) honyerwa } \\
\text { (murmured consonant) }\end{array}$ & Breathy-voiced consonant & $\begin{array}{l}\text { m,- mhara } \\
\text { n, -nhaka }\end{array}$ \\
\hline
\end{tabular}

Adapted from Makaudze, G. (2005, p.2)

It should be noted that the composition above seems to make more sense when the created term is preceded by the word 'nzvanyira' (consonant). "It is hoped that, with the consonant use, the terms zevezerwa, nhamba, sundwa, honyerwa and others of a similar creation can be understood as referring to the given consonants with the juxtaposed use of the term nzvanyira" (Makaudze, 2005, p. 2).

Semantic extension is one other useful method of term creation being employed at Great Zimbabwe University. This is the extension of existing terms to designate new concepts whereby terms that already exist in a language and are used to refer to certain aspects and concepts can have their meanings widened to include the new concepts that are coming into the language. For example, most of the terms used for the organs of speech in English can have equivalent names extended in Shona, though the terms are not phonetic. These 'natural 'terms can have their meanings extended to include even the phonetic references. In English lips are phonetically known as labials or bilabial, the teeth as dentals 
(Makaudze, 2005). For Shona, the common terms' meanings can then be used to mean the concept as given in table 11 below:

TABLE 11

SEMANTIC EXTENSION

\begin{tabular}{|l|l|}
\hline Chishona & English \\
\hline miromo(miviri) & labials/bilabials/lips \\
\hline Mazino & dentals/teeth \\
\hline Chidikwadikwa & Velum \\
\hline Rushizhiro & Glottis \\
\hline Mukanwa & oral cavity \\
\hline
\end{tabular}

The terms created are derived from the function of the signified concepts. There are advantages realized in extending the use of common words to include phonetic concepts. Since the words are already in use in the indigenous language, they are common and accessible to most of the Shona speakers. Their use in phonetics will therefore, spark little if any controversy. Again, the existing literature already carries some, if not all of these terms such that, "to opt for totally new and different terms just for want of something 'phonetic' would not just warrant speakers' outcry, but would also be counter-productive..." (Makaudze, 2005, p.3). The use of semantic extension to create terms for various concepts also seems easy and is being helpful in the various Shona courses at GZU.

\section{IMPLICATIONS OF GREAT ZIMBABWE UNIVERSITY’ EFFORTS}

It is being recognized that, the Shona language, as a result of language raising efforts, is being used more in business, central and local government, commerce, industry, mining, agriculture, education, advertisements, broadcasting and television. Several socio-cultural, economic and political factors have resulted in the use of Shona, once a low variety in a diglossic relationship with English in Zimbabwe. The factors include Black empowerment/indigenization, the local content policy in broadcasting and the Education Act.

In education, the teaching of Shona in high schools and some tertiary institutions is now in the medium of Shona. Public examinations for Shona in high schools are now being set and written in Shona. All instructions for these examinations are in the same language. There is Shona for Beginners, Intermediate Shona and Advanced Shona being offered at Harare Polytechnic and Specis College. According to Mapara and Nyota, (2007) "these developments point towards the growth and expansion of Shona. This is diglossia leakage because Shona is now used in some formal sectors which previously were the preserve of English in Zimbabwe... (p.385).

In the advertising industry Shona has encroached into an area where English has traditionally been dominating. The impact of language raising efforts is seen in Shona advertisements as can be seen in electronic and print media or even billboards. Mapara and Nyota (2007)'s research in advertisements has discovered that, "both multinational corporates and indigenous ones show an increased interest in Shona advertisements helping them to reach out to the bulk of the Shona population. The success of diglossia leakage in advertising points out to the possible use of Shona in other areas besides education and local government that were also once dominated by English..."(p.394). The National Cultural Policy of 1996 notes that Zimbabwe's indigenous languages constitute a rich linguistic and literary heritage for all people and should provide fertile ground to prove that any language is capable of rising to a dominant position. There are now numerous advertisements in Shona and Ndebele languages which is an area that focus must be put as this tends to show how the country's economy operates.

Mapara and Nyota(2007) argue that, radio and television broadcasts now have $75 \%$ local content, but in the majority of cases it is only music that dominates the indigenous language sphere since there are few indigenous programmes in drama, soap and films. Zimbabwe's Radios 2 and 4 have Shona and Ndebele dominating while Radio 4 also broadcasts Chewa, Kalanga, Shangani, Tonga and Venda (2 hours 15minutes) per week. The language composition in the print media has since changed greatly with the local languages being given much space. The newspaper Kwayedza/Umthunywa has since been separated into two newspapers, namely Kwayedza (for Shona) and Umthunywa (for Ndebele.)

\section{CONCLUSION}

This paper sets out to explore possibilities of using Shona language as a medium of instruction at university level as a way of considering empowerment through language. Findings in this research show that, lack of relevant terminology was identified as the major challenge in the use of Shona as a medium of instruction at university level. This research has confirmed that, the use of mother tongue at university level may lead to its use in the public domains empowering indigenous speakers to participate in the activities of their nation. The use of indigenous languages in wider domains elaborates the languages bringing in new technical terms.

A multilingual approach whereby indigenous languages are recognized and enhanced without downgrading excolonial languages is proposed because it upholds the principle of unity in diversity. It is the recommendation of this research that empowerment of the indigenous languages should not translate into exclusion of English. Such a scenario would bring about reverse discrimination, which is a bad practice. Empowerment through language should simply 
translate into taking advantage or capitalizing on all the languages a nation possesses. In a developing country like Zimbabwe, English and local languages complement each other (Ngara, 1982).

This research has been helpful in shading light to the pitfalls in the use of the mother tongue in learning at university level. It has shown that given resources, time and will, Shona can be used successfully as a medium of instruction at university level. The issue of change in the medium of instruction needs a gradual approach rather than a radical one. It is therefore encouraged that further investigations be carried out to build on evidence already gathered which could be used to influence the policy makers. Although lecturers and students have some problems in implementing the coined and borrowed terms, it is evident that given time, this problem becomes insignificant. The findings from this study confirm that despite these problems, given time and adequate resources, mother tongue instruction can be used at university level in learning Shona. The success of Somali language in Somalia, Creole in Seychelles (Brock-Urtne, 1993), successful experimentation of Yoruba in teaching Biology, Mathematics and History in Nigeria (Bamgbose, 1991) are all evident to the possibility of using mother tongues in education and even across the curriculum.

\section{REFERENCES}

[1] Anyidoho, K. (1992). "Language and Development Strategy in Pan-African Literary experience". In Research in African Literatures Vol. 23 p $45-63$.

[2] Chabata, E. (2008). "Language development: Progress and challenges in multilingual Zimbabwe." in Southern African linguistics and applied language studies. South Africa: NISC Private Limited.

[3] Chapanga, E. and Makamani, R. (2006). "Teaching Shona in English/Shona: Ideological challenges and implications Whither U.Z.and MASU?'In Zimbabwe Journal of Educational research. Volume 18 no.3 pp383-397.

[4] Chimhundu, H. (2002). Adoption and adaption in Shona. Oslo: ALLEX project.

[5] Chimhundu, H. (ed) (2003). African Languages Research Institute (ALRI) Report on the Retreat to Review the Allex Project. Harare, University of Zimbabwe.

[6] Chimhundu, H. (2005) "Lexicography and language raising: Dictionaries in Zimbabwean languages."(Public lecture delivered as part of the golden jubilee celebrations of the University of Zimbabwe, Harare.)

[7] Chiwome, E.M. (1992). 'Term Creation: The Case of Shona', in Crawhall(ed) Democratically speaking: International perspectives on Language planning. South Africa: National Language Project.

[8] Cummins, J. (1984). Bilingualism and special education: Issues in assessment and pedagogy. Clevdon: Multilingual Matters.

[9] Cummins, J. (2000). Language power and pedagogy: Bilingual children in the crossfire. Clevedon: Multilingual Matters.

[10] Hadebe, S. (2006). The Standardization of the Ndebele language through dictionary making. University of Oslo: Allex Project.

[11] Hamers, J and Blanc, M. (1992). Bilingualism and Bilingualism. Cambridge, Cambridge University Press.

[12] Hymes, D. (1974). Foundations in sociolinguistics: An ethnographic approach. Philadelphia.

[13] Kroll, B. (1990). Second Language Writing Research. Insights for the Classroom. Cambridge: Cambridge University Press.

[14] Makanda, A.P.T. (2009). The Language question in Africa: Zimbabwe a case study. University of .South Africa. Masters of Arts Dissertation.

[15] Makaudze, G. (2005). "Creating lexicon to teach ChiShona in ChiShona at university: A look into the linguistic dimension of the language." Unpublished Paper presented at Great Zimbabwe University.

[16] Mapara, J. and Nyota, S. (2007). "The impact of lexicographical work on language use: The case of Shona monolingual dictionaries in Zimbabwe" in Afrilex Reeks/series 17.Stellenbosch: Bureau of the Wat.

[17] Mavesera, M. (2009). "Empowerment through language: Exploring possibilities of using African languages and literature to promote socio-cultural and economic development in Zimbabwe." Doctor of Philosophy thesis: University of South Africa.

[18] Mheta, G. (2007). "Strategies employed in the development of Shona musical terms.": University of Zimbabwe. Masters of Philosophy Dissertation

[19] Mutasa, D.E. and Ogutu, E.E. (2008). Teaching and Administering in African Languages: A Road Map to African Renaissance. Brooklyn Square: Simbaguru Publishers.

[20] Ndamba, G.T. (2008). "Mother Tongue Usage in Learning: An Examination of Language Preferences", in Zimbabwe. The Journal of Pan African Studies. 2(4), 171-188.

[21] Ngara, E.A. (1982). Bilingualism, Language Contact and Language Planning. Proposal for Language Use and Language Teaching in Zimbabwe. Gweru: Mambo Press.

[22] Ngugi wa Thiong'o. (1987). Decolonizing the Mind. The Politics of Language in African Literature. Harare: Zimbabwe Publishing House.

[23] Ngugi wa Thiong'o. (1981). Education for a National Culture. Harare: Jongwe Publishers.

[24] Otto, D. (1997). First Language Maintenance in a Second Language Context. Paper presented at the Regional Conference on Early Childhood Education in Higher Education: The way forward. Kadoma, Zimbabwe.

[25] Prah, K.K. (2002). Rehabilitating African Languages: Language Use, Language Policy and Literacy in Africa. Cape Town: the Centre for Advanced Studies of African Society.

[26] Roller, C. (1988). Transfer of Cognitive Competence and L2 Reading in a Rural Zimbabwean Primary School. TOSEL: Quarterly. 22 p. 303-319

[27] Rwambiwa, J.P. (1996). "Indigenous Languages: An Answer towards economic Independence- A Simpler case for Zimbabwe. Towards Capacity Building in Science and Technology." Paper presented to the 5th Symposium of the Research Council of Zimbabwe. 24-26 September 1996. Harare.

[28] Sager, J. (1990). A Practical course in terminology processing. Amsterdam: John Benjamins.

[29] Uju, C.C. (2008). Language Science, Technology, and Mathematics TM and Poverty Alleviation in Africa: A Case of Nigeria in Zimbabwe Journal of Educational Research Volume 20(1): 22-29. Zimbabwe Education ACT Chapter 25:04. Revised Edition 1996. Harare: Government Printers. 
[30] UNESCO. (1999). Review of Educational Sector Analysis in Zimbabwe. (1990-1996): Paris: UNESCO.

Mickson Mazuruse was born in Masvingo, Zimbabwe on 22 November 1967. He graduated with an Honours degree in African Languages and Literature at the University of Zimbabwe in Harare, Zimbabwe in 1990. He completed his Master's African Languages and Literature in the same Department in 2010.He also possesses another Masters degree by research in African languages and literature with the University of South Africa 2010. He is currently studying for a Doctor of Philosophy degree in African Languages with the University of South Africa.

$\mathrm{He}$ is a Lecturer in the Department of Curriculum studies at the University of Zimbabwe where he teaches Socio-linguistics, Literature and Language Planning. He has taught in secondary school for fifteen years and at college for six years. He has coauthored two chapters in a book published by Mambo Press in Zimbabwe on "Grammar at 'A' Level: A student's Handbook". He is currently the Deputy National Chief Examiner for 'A' level Shona Paper 2 with components of Grammar and Practical Criticism. Research interests are in the fields of Language Planning, Morphology and Applied linguistics.

Mr Mazuruse is the treasurer of Shona Language and Cultural Association which is an association whose major objective is to see to it that language and cultural issues are given their rightful place in the education system.

Edgar Nhira Mberi was born in Rusape, Zimbabwe on the $6^{\text {th }}$ of June 1965. He graduated with an Honours degree in African Langauges and Literature at the University of Zimbabwe in Harare, Zimbabwe in 1987. He completed his Master's African Languages and Literature in the same Department in 1990. He went on to study for a Doctor of Philosophy degree in African Languages on a sandwich model involving the University of Oslo in Norway and the University of Zimbabwe and he graduated in 2003.

$\mathrm{He}$ is a Lecturer in the Department of African Languages and Literature at the University of Zimbabwe where he teaches Dialectology, Language Change and Language Planning. He is a former Chairman of the Department.

Dr Mberi was the deputy editor of the corpus-aided Shona monolingual dictionary DuramazwiReChiShona Harare, Zimbabwe, College Press, 1996. He is member of the Linguistics Association of SADC universities (LASU). He is currently a member of the Cross-BoarderLanguges Project which is aimed at researching into languages that cross the Zimbabwe-Mozambique boarder, a project in which the University of Zimbabwe collaborates with the Eduardo Mondlane University in Maputo, Mozambique. 